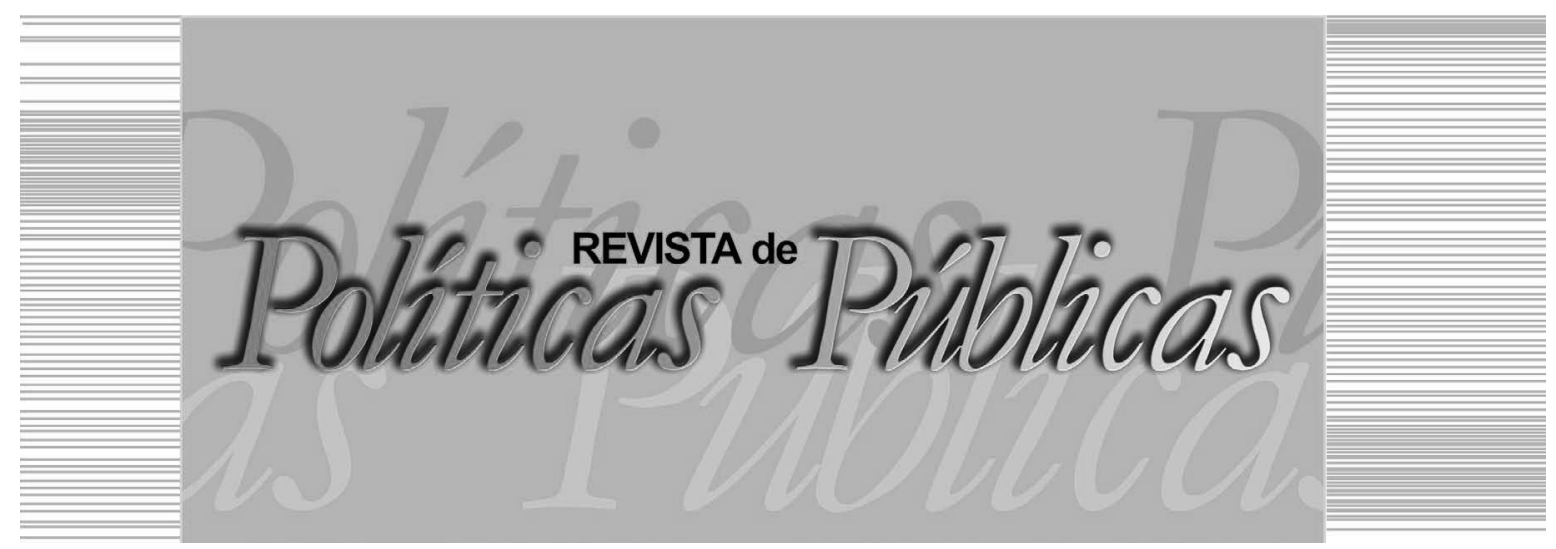

\title{
TRABALHO, ALIENAÇÃO E ADOECIMENTO MENTAL: as metamorfoses no mundo do trabalho e seus reflexos na saúde mental dos trabalhadores
}

\section{Maiara Reis Campos ${ }^{l}$}

\section{Resumo}

Este artigo apresenta uma revisão de literatura sobre a categoria trabalho e suas metamorfoses históricas, desde a sua concepção enquanto categoria ontologia central do processo de humanização do homem, aos dias atuais. Nesse percurso, intensifica-se o fenômeno alienação, onde o homem perde gradativamente o seu potencial criativo, opera conforme os ditames do capital, produzindo algo que lhe é estranho. A contemporaneidade traz novas roupagens para a alienação que se apresenta como mecanismos de captura da subjetividade do trabalhador, ao passo que este se degrada física e mentalmente. Este artigo é fruto de proposta de pesquisa qualitativa sobre esta temática e compõe o projeto de dissertação apresentado ao Mestrado Acadêmico em Serviço Social, Trabalho e Questão Social.

Palavras-chave: Trabalho, alienação, adoecimento mental.

WORK, ALIENATION AND MENTAL ILLNESS: the metamorphoses in the world of work and its reflections on workers' mental health

\section{Abstract}

This article presents a literature review on the work category and its historical metamorphoses, from its conception as a central ontology category of the hu-

\footnotetext{
Assistente Social, Mestranda em Serviço Social, Trabalho e Questão Social pela Universidade Estadual do Ceará (UFC). Email: maiarareisc@gmail.com / Universidade Estadual do Ceará - UFC: Av. da Universidade, 2853, Benfica, Fortaleza - CE. CEP. 60020-181.
} 
manization process of man, to the present day. In this way the phenomenon of alienation intensifies, where man gradually loses his creative potential, operates according to the dictates of capital, producing something that is foreign to him. Contemporaneity brings new garments for alienation that present itself as mechanisms to capture the subjectivity of the worker, while the latter, is degraded physically and mentally. This article is the result of a qualitative research proposal on this subject and composes the dissertation project submitted to the MSc in Social Work, Work and Social Issues.

Key words: Work, alienation, mental illness.

\section{INTRODUÇÃO}

A sociedade contemporânea tem sido marcada por transformações estruturais nos campos econômico, político, social e cultural, com reflexos diretos no mundo do trabalho e nas relações sociais. $\mathrm{O}$ capital internacionalizado torna ainda mais viva a Lei Geral da Acumulação Capitalista (MARX, 1996) na medida em que potencializa em níveis exorbitantes o acúmulo de riquezas de um lado e, no outro polo, a concentração de pobreza em suas diversas manifestações, inaugurando novos arranjos para a questão social.

Para superar a crise referida, o padrão de acumulação capitalista passa por um processo de transformação, denominado de reestruturação produtiva ${ }^{1}$, impulsionado pelo incremento de tecnologias de ponta, dando início ao período da acumulação flexível sob o domínio do capital financeiro.

A era flexível do capital tem demonstrado seu caráter deletério para a classe trabalhadora, objetiva e subjetivamente. Marcado pela empresa enxuta, o toyotismo inaugura uma nova forma de organização e gestão do trabalho, onde emergem novas formas de precarização. Os trabalhadores se veem imersos em um quadro de desemprego estrutural que os compromete diretamente, aumentando a subordinação destes aos ditames do capital. Estamos vivenciando a intensificação dos processos de exploração e, principalmente, de alienação, já expostos por Marx em seus Manuscritos Econômicos Filosófico de 1844, agora sob uma nova roupagem que marca a era do capitalismo manipulatório que não apenas aliena, mas captura a subjetividade do trabalhador - o controle da consciência.

Sobre este assunto, temos nas declarações de Alves (2013, p. 10), que a crise contemporânea tomou novas dimensões, apresentando-se nos mais diversos campos, "[...] crise da vida pessoal, crise de 
TRABALHO, ALIENAÇÃO E SOFRIMENTO MENTAL: revisão de literatura sobre as metamorfoses do mundo do trabalho e seus reflexos da saúde mental do trabalhador

sociabilidade e crise da sociabilidade e crise de autorreferência pessoal; dessubjetivação de classe, captura da subjetividade do homem-que-trabalha, condição de propriedade [...]".

Assim, a classe trabalhadora tornou-se ainda mais vulnerável a situações estressoras. A exigência da polivalência, a pressão pelo aumento da produtividade, associada à contenção salarial, à instabilidade no trabalho, jornadas prolongadas e o medo do desemprego implicam em sofrimento no trabalho e na falta deste, acarretando doenças tanto físicas, como psíquicas, que afetam a subjetividade do trabalhador, podendo levar ao desencadeamento de adoecimento mental, o que tem sido um fenômeno facilmente observável no cotidiano dos Centros de Atenção Psicossocial ${ }^{2}$ (CAPS) e que vem sendo bastante explorado atualmente, ganhando destaque em pesquisas científicas e na mídia.

Pelos dados da Organização Mundial de Saúde (OMS), verifica-se que os transtornos mentais que afetam a classe trabalhadora têm crescido a cada ano. Segundo Teixeira (2007), dados da Previdência evidenciam que os transtornos mentais ocupam o terceiro lugar entre as causas para a concessão de benefícios relacionados à incapacidade no trabalho. Nesse sentido, torna-se imperativo desvendar os fenômenos macroestruturais que perpassam este campo, uma vez que compreendemos que para além de questões da subjetividade humana, este apresenta reflexos diretos da nova dinâmica do capital contemporâneo.

\title{
2 DOS MÚLTIPLOS SENTIDOS DO TRABALHO: da
}

\author{
ontologia do ser social à precarização total
}

Nas palavras de Marx (1996, p. 297), “[...] o trabalho é um processo entre o homem e a natureza, um processo em que o homem, por sua própria ação, media, regula e controla seu metabolismo com a natureza". Por ser uma relação dialética que permite a transformação de ambos, onde o homem transforma a natureza para alcançar suas necessidades desde as mais elementares às mais complexas, num constante intercâmbio, possibilita a reprodução do próprio homem.

A partir do trabalho "[...] o homem deixa a condição de ser natural para tornar-se pessoa humana, transforma-se de espécie animal que alcançou certo grau de desenvolvimento relativamente elevado em gênero humano, em humanidade.” (LUKÁCS, 1978, p. 15). 
O trabalho, em sentido ontológico, é inerente a todos os seres humanos, tendo uma finalidade racionalmente pré-idealizada, sendo o mesmo ineliminável na vida do homem. É uma ação teleológica e consciente que busca uma finalidade, sendo a categoria fundante da reprodução social. O trabalho representa todas as condições, sejam objetivas ou subjetivas, para a sobrevivência do ser humano, pois é a partir dele que o homem se realiza e supre as suas necessidades socio-históricas.

Esse processo de trabalho envolve a capacidade de pensar, planejar e objetivar o futuro. Para Marx (1996), esse elemento é o que difere o trabalho humano daquele que seja de qualquer outro animal: é a possibilidade da prévia ideação, como uma ação teleologicamente direcionada, com um objetivo preestabelecido no plano das ideias, para, enfim, se materializar. Sendo previamente idealizado, ao atingir os seus objetivos no final do processo produtivo, o homem se reconhece naquilo que produziu, o que gera satisfação e prazer.

Nessa mesma direção, Lukács (1978) completa que o sujeito que trabalha realiza uma posição teleológica de modo consciente, e é justamente essa característica do trabalho humano que o torna diferente de qualquer atividade meramente biológica. Nessa práxis, o produto já existia de modo ideal antes mesmo de sua produção, demandando inclusive os meios necessários para sua concretização no plano real. E é nesse sentido que o conhecimento dos meios adequados para alcance das finalidades do trabalho é primordial para o ser social.

Do mesmo modo, Lessa (2012, p. 25) destaca que o trabalho “[...] é a categoria fundante do mundo dos homens. É no trabalho que se efetiva o salto ontológico que retira a existência humana das determinações meramente biológicas. Sendo assim, não pode haver existência social sem trabalho". Embora destaque que a existência social seja muito mais que trabalho, este último é apenas partícipe do complexo social que conta com outras mediações, como a fala e a sociabilidade. $\mathrm{O}$ trabalho - atividade tipicamente humana de transformação da natureza - exige necessariamente a relação entre os homens. A vida social é mais que trabalho, na medida em que exige uma enorme variedade de atividades voltadas ao atendimento das necessidades humanas, mas que ainda assim se articulam ao universo do trabalho. 
TRABALHO, ALIENAÇÃO E SOFRIMENTO MENTAL: revisão de literatura sobre as metamorfoses do mundo do trabalho e seus reflexos da saúde mental do trabalhador

Recuperando as palavras de Marx, este refere que o trabalho como intercâmbio material com a natureza, atividade eternamente necessária do homem com a natureza é fundamentalmente distinta do trabalho abstrato - produtor de mais-valia. Entretanto, o próprio trabalho vem sendo convertido na imediaticidade do cotidiano transformando-se em produtor de mais-valia. Lessa (2012, p. 26, grifo do autor) concentra seus esforços em defender a profunda diferença entre trabalho e trabalho abstrato, alertando-nos que o trabalho abstrato

[...] é uma atividade social assalariada, alienada pelo capital. Corresponde à submissão dos homens ao mercado capitalista, forma social que nos transforma a todos em "coisas" (reificação) e articula nossas vidas pelo fetichismo da mercadoria. O trabalho, pelo contrário, é a atividade de transformação da natureza pela qual o homem constrói, concomitantemente, a si próprio como indivíduo e a totalidade social da qual é partícipe. É a categoria decisiva da autoconstrução humana, da elevação dos homens a níveis cada vez mais desenvolvidos de socialidade. Embora a palavra trabalho faça parte das duas categorias, isto não deve velar que há uma enorme distância a separar trabalho de trabalho abstrato.

Assim, na sociedade capitalista o trabalho é explorado e reduzido à condição de alienado: o trabalhador é desumanizado através das relações sociais de produção, sendo necessária a venda da força de trabalho em troca do salário para garantir a sua sobrevivência. (MONTAÑO; DURIGUETTO, 2011). Lessa (2012, p. 26) contribui afirmando que nesse tipo de sociabilidade

[...] praticamente todas as formas de práxis social, com a incorporação, ao processo de valorização do capital, de atividades que anteriormente ou estavam dele excluídas ou apenas participavam de modo muito indireto, vivemos uma situação em que praticamente a totalidade dos atos de trabalho assume a forma abstrata advinda de sua subordinação ao capital. Aparentemente, o trabalho teria desaparecido, substituído pelo trabalho abstrato. Trabalho e trabalho abstrato passam, assim, equivocadamente a ser tomados como sinônimos no caso da sociabilidade contemporânea.

Conforme o modo de produção capitalista se expande, aumenta a incorporação tecnológica e, em consequência, a redução dos postos de trabalho, surgindo uma grande parcela de trabalhadores excluídos do processo produtivo: o exército industrial de reserva ${ }^{3}$. Esse, por sua vez, torna-se determinante para o rebaixamento do trabalho e intensificação da pressão sobre o trabalhador empregado. 
Em constante movimento de crise e expansão, o sistema capitalista passa por inúmeras crises no curso de sua história. Destacamos para efeito deste ensaio a crise da superacumulação que emerge na transição da década de 60 para 70 do século passado e seus efeitos devastadores para a classe trabalhadora.

Nesse sentido, Antunes (2014) nos lembra que já em meados da década de 1960, o fordismo demonstrava sua incapacidade de autopreservação com todo seu aparato rígido que se alastrava da produção, aos mercados e formas de contratação da força de trabalho. Seus "[...] elementos constitutivos básicos eram dados pela produção em massa, através da linha de montagem e de produtos homogêneos". (ANTUNES, 2014, p. 35). O tempo era controlado a partir dos cronômetros e pela produção em série, e carregava ainda como marca a grande quantidade de operários atuando de forma parcelar e fragmentada. $\mathrm{O}$ corpo de trabalho coletivo fortemente organizado impedia qualquer alternativa de alteração na dinâmica fordista para conter seus sinais de esgotamento, como redução de quadro de trabalhadores e rebaixamento salarial. No entanto, diante de uma série de elementos que demarca o fim da era de ouro do capital, como a crise do petróleo em 1970, faz-se necessário modificar as bases de produção.

Em resposta à crise, o padrão de acumulação capitalista passa por um processo de transformação, denominado de reestruturação produtiva, impulsionado pelo incremento de tecnologias de ponta, dando início ao período da acumulação flexível sob o domínio do capital financeiro. Este último passa a exercer um completo domínio sobre toda a vida social, tendo como mola propulsora o avanço tecnológico que permite operações a longas distâncias. Sobre este aspecto, Harvey (2014, p. 154) comenta

A estrutura desse sistema financeiro global alcançou tal grau de complexidade que ultrapassa a compreensão da maioria das pessoas. As fronteiras entre funções distintivas como bancos, corretoras, serviços financeiros, financiamento habitacional, crédito ao consumidor, etc. tornaram-se cada vez mais porosas, ao mesmo tempo que novos mercados futuros de mercadorias, de ações, de moedas ou de dívida surgiram por toda parte, introduzindo o tempo futuro no tempo presente de maneiras estarrecedoras. $\mathrm{O}$ uso de computadores e as comunicações eletrônicas acentuaram a significação da coordenação internacional instantânea de fluxos financeiros. 
TRABALHO, ALIENAÇÃO E SOFRIMENTO MENTAL: revisão de literatura sobre as metamorfoses do mundo do trabalho e seus reflexos da saúde mental do trabalhador

A era flexível surge em contraponto direto à rigidez fordista, a partir de uma série de experiências na organização industrial que perpassa o campo social e político. Esta tem como base a

[...] flexibilidade dos processos de trabalho, dos mercados de trabalho, dos produtos e padrões de consumo. Caracteriza-se pelo surgimento de setores de produção inteiramente novos, novas maneiras de fornecimento de serviços financeiros, novos mercados e, sobretudo, taxas altamente intensificadas de inovação comercial, tecnológica e organizacional. [...] envolve rápidas mudanças dos padrões do desenvolvimento desigual tanto entre os setores como entre as regiões geográficas [...]. (HARVEY, 2014, p. 140).

Esse foi o contexto que retrata o momento em que o modelo fordista/taylorista foi solapado, substituído pelo modelo de produção toyotista que inaugura um novo processo de organização e gestão do trabalho. Nesse novo modelo de produção, a incorporação de tecnologias contribui com o desemprego estrutural e as novas e variadas formas de trabalho, marcadas pelo trabalho temporário e informal, subemprego, terceirização, etc., sob o disfarce da modernização das relações trabalhistas. Ao mesmo tempo há um enfraquecimento da luta operária-sindical, dando margem para o rebaixamento de salários e, consequentemente, perda de direitos sociais.

Esse processo materializa-se na vida da classe trabalhadora que vem sofrendo mudanças impactantes, onde as novas formas de organização do trabalho representam uma desregulamentação e perda de direitos, fragilização da organização e do poder de luta dos sindicatos, precarizando os processos de trabalho. De acordo com Antunes (2014), o contexto atual é marcado por um completo retrocesso nos campos dos direitos trabalhistas, com a presença de diversas estratégias de burlar a legislação vigente e incorporar novas formas juridicamente válidas de regulamentação do trabalho.

Assiste-se, nas ultimas décadas, a um quadro geral de exploração do trabalho como estratégia de acentuar acumulação de capital onde imperam a informalidade e precarização. Nesse terreno, destaco a terceirização como estratégia crescente de desregulamentação dos direitos trabalhistas que vem se configurando como um fenômeno cada vez mais presente no mundo empresarial. Assistimos o aumento exponencial do número de empresas de locação de mão de obra e, ao mesmo tempo, de um conjunto de novos projetos de regulamentar a sociedade da terceirização total. 
Esse processo materializa-se na vida da classe trabalhadora que vem sofrendo mudanças impactantes, submetendo-se a trabalhos precários, temporários, subcontratados, terceirizados etc. Essas novas formas de organização do trabalho representam uma desregulamentação e perda de direitos, fragilização da organização e do poder de luta dos sindicatos, precarizando os processos de trabalho. (ANTUNES, 2009).

Giovani Alves (2010, p. 1) dedica parte considerável de seus estudos à compreensão do mundo do trabalho, sobretudo do "[...] novo caráter da precarização do trabalho que surge com a nova precariedade salarial vigente no capitalismo global". O autor ressalta que seus estudos versam não apenas sobre a precarização do trabalho que se configura nos dias atuais apenas como mera mercadoria, como expressão das novas formas de exploração na era flexível com desmonte de direitos, mas também sobre o avanço na direção da precarização da dimensão humano-genérico. Considerando, ainda, a barbárie social contida nesse processo de crise estrutural do capital e a desconstrução do homem enquanto ser genérico.

Nesse aspecto, o autor explica que o capital invade a vida privada de homens e mulheres que trabalham, reduzindo sua vida pessoal a mero trabalho assalariado, intensificando os processos de alienação. Interfere nas relações sociais e na própria relação do homem consigo mesmo. Nas palavras de Alves (2010, p. 3, grifo do autor)

A nova precariedade salarial, ao alterar a dinâmica da troca metabólica entre os espaço-tempo de vida e espaço-tempo de trabalho, em virtude da "desmedida" da jornada de trabalho, corrói o espaço-tempo de formação de sujeitos humano-genéricos, aprofundando, deste modo, a auto-alienação do homem que trabalha. [...] a incerteza e instabilidade das novas modalidades de contratação salarial e a vigência da remuneração flexível alteram, do mesmo modo, a troca metabólica entre o homem e os outros homens (a dimensão da sociabilidade); e entre o homem e si-próprio (a dimensão da auto-referência pessoal). Deste modo, a precarização do trabalho e a precarização do homem que trabalha implicam a abertura de uma tríplice crise da subjetividade humana: a crise da vida pessoal, a crise de sociabilidade e a crise de auto-referência pessoal. 
TRABALHO, ALIENAÇÃO E SOFRIMENTO MENTAL: revisão de literatura sobre as metamorfoses do mundo do trabalho e seus reflexos da saúde mental do trabalhador

\title{
3 ALIENACC̃̃O E ADOECIMENTO MENTAL DO
}

TRABALHADOR: efeitos contemporâneos da crise estrutural do capital e suas estratégias de superação

O trabalho, que é elemento central na vida do homem, no decorrer da história e do desenvolvimento das sociedades, passa a não mais satisfazê-lo, transforma-se em uma relação de exploração entre classes sociais. A alienação aparece como fator determinante desse novo processo de trabalho, em que o trabalhador deixa de se reconhecer no objeto produzido. A perda da identidade do trabalhador com o produto de seu trabalho dar-se-á como um estranhamento; o resultado do trabalho se expressa como alheio e sem intimidade com seu produtor, enquanto esse se torna inferior e adversário. (MARX, 1996). Além de estranho, o objeto passa a ser dotado de poder independente de quem o produziu.

\begin{abstract}
O produto do trabalho é o trabalho que se fixou num objeto, fez-se coisa (sachlich), é a objetivação (Vergegenständilichung) do trabalho. A efetivação (Verwirkichung) do trabalho é a sua objetivação. Esta efetivação do trabalho aparece ao estado nacional-econômico como desefetivação (Entwirlichung) do trabalhador, a objetivação como perda do objeto e servidão ao objeto, a apropriação como estranhamento (Entfremdung), como alienação (Entäusserung). (MARX, 2010, p. 80).
\end{abstract}

Quanto mais riqueza produz, mais pobre o trabalhador se torna. Constitui-se, enquanto mercadoria, mais miserável do que qualquer outra, mais barata e mais desvalorizada. No capital temos uma completa inversão de valores; à medida que o mundo das coisas passa a ser super valorizado, a humanidade sofre uma completa degradação. Quanto mais objetos o trabalhador produz, menos dispõe de condições para possuí-los e tanto mais fica imbuído nos mecanismos de dominação do capital, aliena-se em si mesmo, deixando de se pertencer.

A partir da análise de Marx (2010), temos que o trabalho - ontologicamente compreendido como um processo teleológico, criador e transformador, capaz de objetivar aquilo antes idealizado - pelas vias da alienação deixa de pertencer ao sujeito que o produz. O produto agora estranhado tem vida externa, existe fora do trabalhador como potência autônoma. $\mathrm{O}$ estranhamento aparece não apenas com relação ao objeto final, mas desde o primeiro momento da produção todos os atos de sua elaboração são externos a quem o produz. 
Na avaliação de Mészáros (2006), a crítica da alienação é assunto da ordem do dia, assumindo caráter de urgência diante das suas manifestações contemporâneas. Ao analisar a obra marxista, o referido autor nos informa que o pensamento do teórico alemão parte do conceito de Aufhebung ${ }^{4}$, sendo esse conceito a chave para a compreensão da alienação. É entendido como movimento de transcedência da autoalienação no trabalho, necessário para a mudança de posição para superações da contradição do atual estado das coisas que conformam o sistema da alienação, apontando, ainda, a necessidade primordial de união entre teoria e prática.

A ideia central do sistema de Marx, já identificada por Lenin e confirmada por Mészáros (2006, p. 92) é a "[...] crítica da reificação capitalista das relações sociais de produção, da alienação do trabalho por meio das mediações reificadas do trabalho assalariado, da propriedade privada e do intercâmbio". A alienação no trabalho é a raiz causal de todo o complexo de alienação.

Igualmente, Alves apresenta suas considerações sobre o fenômeno da alienação na contemporaneidade, destacando o caráter corrosivo das relações flexíveis para os trabalhadores, atingindo não apenas sua dimensão material - objetiva, mas também o campo da subjetividade. O autor destaca que a alienação/estranhamento se configura hoje como elemento central da investigação marxista, "[...] é o tema candente a partir do qual se deve elaborar a crítica do capital como modo de controle estranhado do metabolismo social e a reflexão necessária sobre as possibilidades históricas da emancipação humana nas condições da barbárie social.” (ALVES, 2013, p. 58).

Afirma o autor que nas ultimas décadas observamos uma reestruturação cultural de caráter neoconservador marcada pela intensificação do fetichismo das mercadorias que, como em nenhum outro momento do capital, valem mais que o homem/mulher que as produz. Além disso, a produção de mais-valia absorve quase a totalidade das atividades assalariadas, implicando a ampliação do trabalho abstrato.

A transformação das pessoas em mercadoria e a implicação da vida para o consumo no seio da "sociedade do espetáculo" alterou a qualidade-densidade do movimento histórico da "classe", promovendo a universalização da "condição de proletariedade" capaz de abrir novas possibilidades objetivas para a formação da consciên- 
TRABALHO, ALIENAÇÃO E SOFRIMENTO MENTAL: revisão de literatura sobre as metamorfoses do mundo do trabalho e seus reflexos da saúde mental do trabalhador

cia de classe e, por conseguinte, da própria classe social do proletariado. Entretanto, alterou-se o registro histórico da Aufhebung na medida em que a voracidade da manipulação assumiu dimensões qualitativamente novas no plano da subjetividade das massas, obstaculizando ou retardando a formação e constituição do sujeito humano capaz de dar resposta radical à condição de proletariedade. (ALVES, 2013, p. 4, grifos do autor).

É na vida cotidiana que nascem as possibilidades de emancipação humana. No entanto, essa dimensão é invadida de forma mais intensa na fase manipulatória ${ }^{5}$ do capitalismo, impedindo a formação dos sujeitos enquanto classe capaz de responder criticamente às investidas do capital, na perspectiva de sua superação. Atingir o campo da subjetividade implica redução da capacidade de resistência e luta pela autonomia radical da classe trabalhadora. O processo de manipulação combina elementos de coerção e consenso que se estendem para além do local de trabalho. Vão desde as constantes ameaças da perda do emprego, diante do volume de mão de obra sobrante, até as estratégias de reprodução de valores-fetiches ${ }^{6}$.

A "captura" da subjetividade é a "captura" da intersubjetividade e das relações sociais constitutivas do ser genérico do homem. É ela que explica o movimento de dissolução de coletivos de trabalho e reconstrução de novos coletivos/equipes ditas "colaborativas" com as idéias da empresa. [...] ela não é apenas controle/manipulação das instâncias psíquicas do sujeito burguês, do homem que trabalha, apreendido como uma mônoda social, mas a corrosão/ inversão/perversão do ser genérico do homem como ser social. (ALVES, 2013, p. 13, grifos do autor).

Nos dias atuais, com a possibilidade do uso de tecnologias, o que temos é a exaustão das estratégias de manipulação que perpassam os campos intrapsíquicos através de um intenso fluxo de informações pela via das redes de internet, televisão, celular e outras mídias que alcancem todas as classes sociais.

Os valores-fetiche da produção transpassam a barreira dos muros das organizações e perpassam todos os espaços de sociabilidade e, neste caminhar, todo o corpo de empregados submetidos à lógica da manipulação acaba sofrendo prejuízos físicos que, de forma ainda mais devastadora, atingem a ordem psíquica e espiritual, manifestando-se em sintomas psicossomáticos. Nesse contexto, o trabalho, como expressão da alienação, deixa de ser fonte de realização do homem e passa a gerar sérios prejuízos à saúde do trabalhador. (ALVES, 2013). 
Na contemporaneidade, diante da intensificação de precarização do trabalho, verifica-se que o adoecimento tanto físico como mental surgem como respostas geradas pelas próprias condições do processo produtivo de flexibilização. $\mathrm{O}$ trabalhador passa a apresentar diversas queixas como angústia, insônia, ansiedade, agitação, desânimo, medo, agressividade, sufocamento, isolamento social, associando tais sintomas às condições de trabalho. (NAVARRO; PRAZERES, 2010).

Alves (2011, p. 152-153, grifos do autor) nos diz que “[...] as novas práticas sociometabólicas da sociedade neoliberal tendem a constituir 'subjetividades precárias' ou 'subjetividade em desefetivação' atingidas pelo estresse”. Nesse aspecto, utilizando dados da Organização Mundial de Saúde (OMS) que expressam um verdadeiro surto de estresse que atinge a sociedade capitalista contemporânea, o referido autor enfatiza que

[...] o estresse é uma das maiores ameaças à saúde humana no século XXI [...] pode -se dizer que o estresse é a doença universal da sociedade toyotizada. É uma síndrome que atinge corpo e mente e que expressa o caráter totalitário e totalizante das novas implicações objetivas (subjetivas) da produção do capital. O estresse é sintoma epidemiológico do sociometabolismo da barbárie e das novas condições da produção do valor. É decorrente do espírito do toyotismo que exige, no contexto de um novo patamar de racionalização do trabalho, a "captura" da subjetividade do trabalhador, capaz de operar os novos dispositivos técnico-organizacionais da produção de mercadorias. (ALVES, 2011, p. 152-153, grifo do autor).

Neste sentido, cabe destacar que o adoecimento mental do trabalhador pode se manifestar de diversas formas que não são consideradas enquanto quadro psicopatológico definido, mas que ainda assim merecem ser fruto de estudo e atenção especial por parte de pesquisadores e trabalhadores do campo da saúde mental do trabalho.

Seligmann-Silva (2011) revela a intrínseca relação entre trabalho e adoecimento mental, principalmente relacionado às transformações contemporâneas no mundo do trabalho e as marcas da precarização total que atingem não apenas os processos de trabalho, mas avançam para os campos da vida familiar, dos vínculos interpessoais, do lazer e da participação social, ou seja, atinge toda a sociabilidade humana. 
TRABALHO, ALIENAÇÃO E SOFRIMENTO MENTAL: revisão de literatura sobre as metamorfoses do mundo do trabalho e seus reflexos da saúde mental do trabalhador

\section{CONCLUSÃO}

Compreendemos que o fator trabalho e suas configurações contemporâneas não são os únicos responsáveis pelo adoecimento mental do trabalhador, uma vez que este é multifatorial. No entanto, a partir da revisão de literatura apresentada anteriormente é notável que todos esses fatores supracitados incidem diretamente no desencadeamento dos transtornos mentais que afetam os trabalhadores na contemporaneidade. Fatores esses ligados à sociabilidade capitalista de precarização, subordinação e alienação impostas à classe trabalhadora. E, diante da conjuntura atual, entendemos que esse campo merece investigações a fim de elucidar outros fatores.

Partimos da compreensão de que a Saúde Mental está para além da ausência de doença psíquica. Concordamos com a OMS (2001) que a entende como um completo estado de bem-estar físico, mental e social, que possibilita ao indivíduo a realização de suas capacidades, lidando com o estresse da vida cotidiana. Compreende um nível de qualidade de vida cognitiva ou emocional.

A partir do Relatório Mundial Sobre a Saúde no Mundo da OMS (2001) percebemos os alarmantes dados sobre adoecimento mental, produzindo um considerável quantitativo de pessoas incapacitadas para o trabalho. O sofrimento não é o mesmo que dor; embora esta possa levar o indivíduo ao sofrimento, faz parte da complexidade da dimensão subjetiva da humanidade. No entanto, o que nos chama atenção, é o quanto esse vem sendo metamorfoseado em adoecimento, principalmente relacionado ao trabalho.

Assim, ao abordar a categoria saúde mental, nesta pesquisa, intentamos empreender um estudo partindo da suposição de que as transformações no mundo do trabalho contemporâneo refletem na produção de adoecimento mental da classe trabalhadora, uma vez que percebemos no dia a dia dos serviços de atenção psicossocial uma grande demanda de trabalhadores que apresentam queixas de adoecimento mental em virtude das condições de trabalho que vivenciam no cotidiano, ou, ainda, pela falta de trabalho, que é uma marca típica do mundo do trabalho contemporâneo.

\section{REFERÊNCIAS}

ALVES G. Marxismo, a alienação e o tempo histórico da barbárie social do capital. Revista Katálysis, Florianópolis, v. 16, n. 1, p. 57- 
62, jan./jun. 2013. Disponível em:<www.giovannialves.org/Artigo_ GIOVANNI\%20ALVES_>. Acesso em: 1 jul. 2016.

. Trabalho e subjetividade: o espírito do toyotismo na era do capitalismo manipulatório. São Paulo: Boitempo Editorial, 2011.

. Trabalho, subjetividade e capitalismo manipulatório: o novo metabolismo social do trabalho e a precarização do homem que trabalha. In: Reunião CIENTÍFICA SOBRE LAS FORMAS ACTUALES DE PRECARIZACIÓN LABORAL EN EL CONTEXTO LATINO-AMERICANO, Buenos Aires, 2010. Trabalhos... Buenos Aires: CONICET, 2010.

ANTUNES, R. Os sentidos do trabalho: ensaios sobre a afirmação e a negação do trabalho. São Paulo: Boitempo, 2009.

. Adeus ao trabalho?: ensaio sobre as metamorfoses e a centralidade no mundo do trabalho. 16. ed. São Paulo: Cortez, 2014.

HARVEY, D. A condição pós-moderna: uma pesquisa sobre as origens da Mudança cultural. Tradução de Adail Ubirajara Sobral e Maria Stela Gonçalves. 25. ed. São Paulo: Loyola, 2014.

LESSA, S. Mundo dos homens: trabalho e ser social. 3. ed.São Paulo: Instituto Lukács, 2012.

LUKÁCS, G. As bases ontológicas da atividade e do pensamento do homem. Revista Temas de Ciências Humanas, São Paulo, n. 4, p. 1-20, 1978.

MARX, K. Manuscritos econômicos-filosóficos. Trad. Jesus Ranieri. 4. reimp. São Paulo: Boitempo, 2010.

. O Capital: crítica da economia política. Tomo I. Trad. Regis Barbosa e Flávio R. Kothe. São Paulo: Editora Nova Cultural, 1996.

MESZÁROS, I. A teoria da alienação em Marx. Trad. Isa Tavares. São Paulo: Boitempo, 2006.

MONTAÑO, C.; DURIGUETO, M. L. Estado, classe e movimento social. 3. ed. São Paulo: Cortez, 2011.

NAVARO, V. L.; PRAZERES, T. Reestruturação produtiva, precarização e saúde do trabalhador na indústria de calçados de Franca (SP). In: SANT' NA, R. et al. (Org.). O avesso do trabalho II: trabalho e precarização e saúde do trabalhador. 1. ed. São Paulo: Expressão Popular, 2010. p 179-196.

ORGANIZAÇÃO MUNDIAL DA SAÚDE. O peso dos transtornos mentais e comportamentais. In: Relatório sobre saúde 
TRABALHO, ALIENAÇÃO E SOFRIMENTO MENTAL: revisão de literatura sobre as metamorfoses do mundo do trabalho e seus reflexos da saúde mental do trabalhador

no mundo 2001: saúde mental - nova concepção, nova esperança. Genebra, 2001. p. 17-45.

SELIGMANN-SILVA, E. Trabalho e desgaste mental: o direito de ser dono de si mesmo. São Paulo: Cortez, 2011.

TEIXEIRA, S. A depressão no meio ambiente do trabalho e sua caracterização como doença do trabalho. Revista do Tribunal Regional do Trabalho, Belo Horizonte, v. 46, n. 76, p. 27-44, jul./dez. 2007.

\section{Notas}

1 A reestruturação produtiva configurou-se como uma estratégia de reverter a crise enfrentada pelo capital na década de 70 , sendo um processo de reorganização do ciclo de produção, preservando as características centrais do modo de produção capitalista. Este é pautado na incorporação de tecnologia de ponta e na exacerbação dos processos de exploração da classe trabalhadora. (ANTUNES, 2009).

2 Os CAPS foram instituídos pela Portaria $\mathrm{n}^{\circ}$ 336, de 19 de fevereiro de 1992 do Ministério da Saúde. São serviços ambulatoriais que surgem com o objetivo de ofertar cuidado a pessoas com transtornos mentais graves e persistentes e às pessoas com necessidades decorrentes do uso de crack, álcool e outras drogas, em sua área territorial. Contam com equipe multiprofissional que atua na ótica da interdisciplinaridade.

3 O exército industrial de reserva é composto pela população trabalhadora excedente, os desempregados, sendo elemento estrutural indispensável ao acúmulo de capital. (MARX, 1996).

4 Há diversas análises e interpretações para o termo mencionado. No universo marxista, o termo representa o movimento histórico posto a partir da alienação, como classe que nega as coisas. Em Meszáros, "[...] a ideia de Aufhebung significa movimento social do sujeito coletivo capaz de negar o estado de coisas existente (o capital), um movimento sociometabólico alternativo, mais propriamente social que político, e, portanto, que nasce por baixo, abrangendo a totalidade da vida social.” (ALVES, 2013, p. 59).

5 Alves (2011), ao mencionar esta fase, refere-se ao momento do capital pós-reestruturação produtiva. $\mathrm{O}$ autor afirma que o modelo toyotista tem uma densidade maior de manipulação. Buscando dominar toda a estrutura intelectual-afetiva do trabalhador, induzindo-o a pensar pró-ativamente como parte integrante da empresa, adaptando-o às novas exigências do Sistema Toyota de Produção.

6 Nas palavras de Alves (2011, p. 90-91, grifo do autor): “[...] a expressão valores-fetiche para caracterizar o conteúdo vocabular-locucional do imperialismo simbólico. Eles são valores, expectativas e utopia de mercado que permeiam o sociometabolismo do capitalismo tardio. [...] Os valores-fetiches permeiam a linguagem social e, numa sociedade midiática como a sociedade burguesa tardia, eles se disseminam com maior intensidade e amplitude. [...] são elementos cruciais na operação da 'captura' da subjetividade no local de trabalho e na vida social". 
